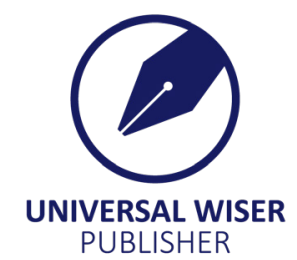

\title{
Physical Properties, Pasting Characteristics and Rheological Behaviour of Paddy Varieties Suitable for Flaking
}

\author{
Dhritiman Saha ${ }^{1^{*}}$, Arun Kumar T.V. ${ }^{2}$, Swati Sethi ${ }^{1}$, Indore Navnath ${ }^{1}$ \\ ${ }^{1}$ Food Grains \& Oilseeds Processing Division, ICAR-Central Institute of Post-Harvest Engineering \& Technology, Ludhiana, Punjab-141004, India \\ ${ }^{2}$ Division of Agricultural Engineering, ICAR-Indian Agricultural Research Institute, New Delhi-110012, India \\ E-mail: dhriti.iitkgp@gmail.com
}

\begin{abstract}
A study was conducted to find the effect of moisture content on various physical properties of paddy varieties (MTU-1010 and BB-11) suitable for flaking. The range of moisture studied was $11.11 \%$ to $28.2 \%$ (d.b.) for both the paddy varieties. The bulk density of the paddy increased from $514.76 \mathrm{~kg} / \mathrm{m}^{3}$ to $563.62 \mathrm{~kg} / \mathrm{m}^{3}$ for MTU-1010 variety and $605.28 \mathrm{~kg} / \mathrm{m}^{3}$ to $632.62 \mathrm{~kg} / \mathrm{m}^{3}$ for BB-11 variety respectively when the moisture content was increased in the experimental range. The sphericity increased from 0.386 to 0.399 for MTU-1010 variety and 0.448 to 0.458 for BB-11 variety with increase in moisture content. The true density and porosity decreased with the increase in moisture content of paddy. The other physical properties such as test weight, surface area, arithmetic mean diameter, geometric mean diameter and angle of repose increased with the increase in moisture content of paddy. The static coefficient of friction of paddy increased with the increase in moisture content on different surfaces e.g. wood, mild steel, and galvanized iron. The regression equations for all the response variables were significant at $\mathrm{P}<0.05$ with coefficient of determination, $\mathrm{R}^{2}(>0.90)$. The amylose content in MTU-1010 and BB-11 variety was found to be $30.23 \%$ and $26.32 \%$ respectively indicating that high amylose containing paddy varieties are generally used for flaking paddy. Further, the pasting properties of both the paddy varieties revealed higher pasting temperature in paddy variety MTU-1010 than BB-11. The rheological studies highlighted higher storage modulus of brown rice than the polished rice for both the paddy varieties.
\end{abstract}

Keywords: flaking, moisture content, physical properties, paddy variety, pasting characteristics, rheological behaviour

\section{Introduction}

India is one of the leading growers of paddy in the world with a production of 112.91 million tonnes during 2017-18 ${ }^{[1]}$. Paddy (Oryza sativa L.), a semi aquatic annual grass grows under variable climatic conditions. The different structural components of paddy grain include husk, bran, and endosperm (rice kernel). Generally, paddy is processed for removing the hull to obtain brown rice before its consumption. Further, milling helps in removing germ and bran from the rice kernel yielding white or polished rice. Different ready to eat rice-based food products are also available in the market. Rice can be consumed by celiac patients as an alternative to wheat-based products due to the absence of gluten ${ }^{[2]}$. It is projected that about $10 \%$ of the total paddy production in India is converted into three rice products namely puffed rice, popped rice and flaked rice ${ }^{[3]}$. Rice flakes is a fast-moving consumer item and generally consumed in combination with spices or with milk or curd. Flaked rice stimulates slow release of sugar into the bloodstream and hence considered as a healthy meal option for diabetic patients. It also contains carbohydrates which are the major source of energy requirement for our body. Most of its preparations can be made easily and hence it is popularly available in most households in India.

The process of flaking involves soaking of paddy, followed by roasting, and flaking in an edge runner to obtained flaked or beaten rice. Different varieties of paddy are used for the purpose of flaking. However, the study of the physical and other properties of the flaking varieties is either limited or not available. The knowledge of the physical properties of different grains can be used for designing various processing equipment ${ }^{[4]}$. The physical dimensions of paddy grains help in selecting sieve sizes and in estimation of power requirement during the process of rice milling. The measured dimensions can also be used to calculate volume of kernels and surface area during modelling of grain drying, soaking, heating, aeration, and cooling ${ }^{[5]}$. The grain's true density, bulk density, and porosity help in designing the hoppers and storage facilities and affect the heat and mass transfer rates of moisture during aeration, drying and soaking processes. The static coefficient of friction is used to determine the angle at which spillway must be designed to get consistent flow

Copyright (C2020 Dhritiman Saha, et al.

DOI: https://doi.org/10.37256/fse.122020617

This is an open-access article distributed under a CC BY license

(Creative Commons Attribution 4.0 International License)

https://creativecommons.org/licenses/by/4.0/ 
of materials through the spillway ${ }^{[6]}$. The grain's pasting and rheological properties gives an indication of the ability of the starch present in rice to resist breakdown and retrogradation which may help in standardizing the soaking and roasting process before the flaking operation. The moisture content of grain also affects the different physical properties of paddy. With the understanding of these facts, the main objective of this research was to determine the physical properties, pasting characteristics and rheological behaviour of traditional flaking varieties of paddy viz., MTU-1010 and BB-11, which would be essential for standardizing the pre-treatment process before flaking and designing of efficient flaking machines to obtain quality flakes as desired by end users.

\section{Materials and methods}

\subsection{Sample preparation and physical measurements}

The paddy variety MTU-1010 \& BB-11 were procured from Bidhan Chandra Krishi Viswavidyalaya, Nadia, West Bengal and Rajendra Prasad Central Agricultural University, Pusa, Bihar respectively. The paddy grains were cleaned through destoner and stored in plastic containers at ambient temperature $\left(25 \pm 5^{\circ} \mathrm{C}\right)$. The moisture content of the paddy samples was evaluated using oven drying at $105 \pm 1{ }^{\circ} \mathrm{C}$ for $24 \mathrm{~h}{ }^{[7]}$. The paddy samples with desired moisture contents were obtained through addition of calculated amount of distilled water followed by sealing in LDPE bags. The distilled water required to be added was obtained using Eq. 1:

$$
Q=\frac{W_{0}\left(M_{f}-M_{0}\right)}{\left(100+M_{0}\right)}
$$

where, Q-water added in $\mathrm{g} ; \mathrm{W}_{0}$-initial sample mass in $\mathrm{g}$; $\mathrm{M}_{0}$-sample initial moisture content (\%, d.b.); and $\mathrm{M}_{\mathrm{f}}$-sample desired moisture content (\%, d.b.). The distribution of moisture uniformly throughout the sample was achieved by placing the samples under refrigerated condition at $5^{\circ} \mathrm{C}$. Prior to conducting the test, pre-determined quantity of the moistened paddy samples were taken out from the refrigerator and kept at ambient temperature for 3 hours ${ }^{[8-11]}$. The physical properties of both the paddy varieties were determined at $11.11 \%, 13.63 \%, 19.04 \%, 25.0 \%$, and $28.20 \%$ moisture content (d.b.). The experiments conducted in this study were repeated thrice with the use of the mean values during analysis. However, for measurement of dimensions, 100 paddy grains were randomly taken at selected moisture contents. The average size of the paddy samples at selected moisture contents was determined through the measurement of the length (L), width (W), and thickness (T) of the grains using a digital vernier calliper with least count of $0.01 \mathrm{~mm}$. The arithmetic mean diameter $(\mathrm{Da})$, geometric mean diameter $(\mathrm{Dg})$ and sphericity $(\varphi)$ were obtained through the following equations ${ }^{[12,13]}$ :

$$
\begin{aligned}
& D_{a}=\frac{(L+W+T)}{3} \\
& D_{g}=(L W T)^{1 / 3} \\
& \varphi=\frac{(L W T)^{1 / 3}}{L}
\end{aligned}
$$

The surface area (As) was obtained by taking a sphere having equal geometric-mean diameter using Eq. $5^{[12]}$ :

$$
A_{s}=\pi D_{g}^{2}
$$

\subsection{Test weight}

The mass of 1,000 paddy grains $\left(\mathrm{M}_{\mathrm{t}}\right)$ was determined by randomly taking about 100 grains and weighing them in an electronic balance having least count of $0.001 \mathrm{~g}$. Thereafter, the counting of number of paddy grains (n) in the sample was done ${ }^{[8]}$. The 1,000 grains mass were obtained as

$$
M_{t}=\frac{M}{n} * 1000
$$




\subsection{Bulk density, true density and bed porosity}

Bulk density $\left(\rho_{\mathrm{b}}\right)$ was determined using AOAC method by filling a $50 \mathrm{~mL}$ cylinder with paddy grains from a height of $0.15 \mathrm{~m}$ at a constant rate followed by weighing of contents in the cylinder. The bulk density was then evaluated as the ratio of weight of paddy grains to the volume displaced. True density $\left(\rho_{t}\right)$ of the paddy grains was calculated through toluene displacement method. Toluene has a low surface tension and hence is used in place of water thereby resulting in low absorption of toluene by paddy grains in comparison to water ${ }^{[12]} .100 \mathrm{~g}$ of paddy grains were submerged in a measuring cylinder $(0.5 \mathrm{~L})$ containing $50 \mathrm{~mL}$ toluene. The displacement in the level of toluene was observed and the true density was determined as the ratio of sample paddy grains mass to the displaced toluene volume ${ }^{[9,12]}$. The bed porosity $(\varepsilon)$ was obtained through Eq. $7^{[12]}$ :

$$
\varepsilon=\left(1-\frac{\rho_{b}}{\rho_{t}}\right) 100
$$

\subsection{Static coefficient of friction}

The static coefficient of friction for the paddy varieties was determined at selected moisture content on different surfaces (mild steel, galvanized iron and plywood). A wooden box having the dimension of $0.1 \mathrm{~m}$ length $\times 0.1 \mathrm{~m}$ width $\times 0.04 \mathrm{~m}$ height with no base and lid was filled with the paddy grains in contact with the test surface and placed on an adjustable tilting plate. The surface angle $(\alpha)$ was observed from the scale at the point the box just start sliding down on tilting the surface. The $\mu$ was determined from Eq. $8^{[9,14]}$ :

$$
\mu=\tan \alpha
$$

\subsection{Angle of repose}

A plywood box of $0.1 \times 0.1 \times 0.1 \mathrm{~m}$ size with a detachable front panel was used for the determination of angle of repose $(\theta)$. The paddy grains were packed in the plywood box followed by the quick removal of the front panel thereby enabling the flow of grains to form a natural slope. The height $(\mathrm{H})$ and diameter (D) of the slope were noted. The angle of repose was then computed by using Eq. $9^{[14,15]}$ :

$$
\theta=\tan ^{-1}\left(\frac{2 H}{D}\right)
$$

\subsection{Amylose content}

The amylose content of MTU-1010 and BB-11 paddy varieties was measured as per standard procedure with minor modifications ${ }^{[16]} .1 \mathrm{~mL}$ of $95 \%$ ethanol and $9 \mathrm{~mL}$ of $1.0 \mathrm{~mol} / \mathrm{L} \mathrm{NaOH}$ was added to $100 \mathrm{mg}$ rice flour followed by overnight incubation at room temperature for starch gelatinization. Distilled water was then added to the samples for dilution to $100 \mathrm{~mL}$. $1 \mathrm{~mL}$ of glacial acetic acid $(1 \mathrm{~mol} / \mathrm{L})$ and $1.5 \mathrm{~mL}$ of iodine solution $(2 \%$ potassium iodide and $0.2 \%$ iodine) was added to $5 \mathrm{~mL}$ aliquot of the suspension and the volume was adjusted to $100 \mathrm{~mL}$ with distilled water. The samples were incubated for $20 \mathrm{~min}$ at room temperature, and the absorbance at $620 \mathrm{~nm}$ was noted. The amylose content of the different accessions was determined with a standard curve of potato amylose.

\subsection{Pasting characteristics}

The pasting characteristics of brown and polished rice flour of both the paddy varieties were measured using Rapid Visco Analyzer (RVA Techmaster, Newport Scientific, Australia). Rice flour samples ( $3 \mathrm{~g}$ ) were made up to $28 \mathrm{~g}$ with distilled water in a RVA canister ( $10 \%$ solids, w/w). The sample suspensions were subjected to heating and cooling cycles for measurement of viscosity. Each experimental sample was kept at $50^{\circ} \mathrm{C}$ for $1 \mathrm{~min}$ with stirring at $960 \mathrm{rev} / \mathrm{min}$ followed by constant stirring at $160 \mathrm{rev} / \mathrm{min}$ while heating the sample from $50^{\circ} \mathrm{C}$ to $95^{\circ} \mathrm{C}$ at the rate of $12^{\circ} \mathrm{C} / \mathrm{min}$, with holding the sample at $95^{\circ} \mathrm{C}$ for $3 \mathrm{~min}$ followed by cooling to $50^{\circ} \mathrm{C}$ at the rate of $12^{\circ} \mathrm{C} / \mathrm{min}$ with holding at $50^{\circ} \mathrm{C}$ for $2 \mathrm{~min}$. The pasting parameters such as trough viscosity (minimum viscosity at $95^{\circ} \mathrm{C}$ ), peak viscosity (maximum viscosity), final viscosity (viscosity at $50^{\circ} \mathrm{C}$ ), breakdown viscosity (peak-trough viscosity), setback viscosity (final-trough viscosity), peak time and pasting temperature were recorded in the form of rapid viscogram. All the measurements were carried out in triplicates. 


\subsection{Dynamic rheological behaviour}

Temperature dependent rheological behaviour of rice flour suspension was evaluated using rheometer (Anton Paar) equipped with Rheoplus software package (RHEOPLUS/32 V3.40 21005317-33024, Anton Paar GmbH, Germany). Rice flour suspension of $2.5 \%$ was prepared and put into the $50 \mathrm{~mm}$ parallel plate testing platform of dynamic rheometer and the samples were analysed for viscoelastic behaviour under oscillation measurement mode with clearance of $1.0 \mathrm{~mm}$. Initially, amplitude sweep test was carried out for identification of the linear viscoelastic region (LVR) and a strain of $1 \%$ was selected for further rheological measurements because amplitude sweep showed a non-linear viscoelastic response beyond this value. After the LVR is obtained, frequency sweep was conducted to determine storage modulus ( $\left.G^{\prime}\right)$ and loss modulus (G') at frequencies ranging from 0.1 to $100 \mathrm{~Hz}$ and a strain of $1 \%$. The excess material was wiped off from the plate edges and samples were kept for suitable time duration, at constant amplitude $(\gamma=1 \%)$ and frequency $(1 \mathrm{~Hz})$. Here, the sample is first heated from $20^{\circ} \mathrm{C}$ to $95^{\circ} \mathrm{C}$ and further subsequently cooled from $95^{\circ} \mathrm{C}$ to $20^{\circ} \mathrm{C}$ at the rate of $5^{\circ} \mathrm{C}$ per second.

\subsection{Statistical analysis}

The experimental data was subjected to one-way analysis of variance test (ANOVA) using the software SPSS 16.0 to analyze the effect of moisture content on the engineering properties of both the paddy varieties. The mean values and standard error for all the properties were calculated using MS Excel 2010.

\section{Results and discussion}

The effect of varied moisture content on true density, bulk density, test weight, sphericity, surface area, arithmetic mean diameter, geometric mean diameter, porosity, static coefficient of friction and angle of repose and were determined in terms of their mean value and standard error (Table 1 and Table 2).

Table 1. Physical properties of MTU-1010 and BB-11 variety at different moisture levels

\begin{tabular}{|c|c|c|c|c|c|c|c|c|c|}
\hline $\begin{array}{c}\text { Moisture content } \\
(\% \mathrm{db})\end{array}$ & $\begin{array}{c}\text { Bulk density } \\
\left(\mathrm{kg} / \mathrm{m}^{3}\right)\end{array}$ & $\begin{array}{c}\text { True density } \\
\left(\mathrm{kg} / \mathrm{m}^{3}\right)\end{array}$ & $\begin{array}{l}\text { Test weight } \\
(\mathrm{g})\end{array}$ & Sphericity & $\begin{array}{c}\text { Surface area } \\
\left(\mathrm{mm}^{2}\right)\end{array}$ & $\begin{array}{l}\text { GMD } \\
(\mathrm{mm})\end{array}$ & $\begin{array}{l}\text { AMD } \\
(\mathrm{mm})\end{array}$ & Porosity & $\operatorname{AOR}\left({ }^{0}\right)$ \\
\hline \multicolumn{10}{|l|}{ MTU-1010 } \\
\hline 11.11 & $514.76 \pm 4.20$ & $1271.61 \pm 6.60$ & $22.25 \pm 2.28$ & $0.386 \pm 0.021$ & $40.92 \pm 1.81$ & $3.6 \pm 0.42$ & $4.61 \pm 0.56$ & $0.60 \pm 0.08$ & $30.96 \pm 2.30$ \\
\hline 13.63 & $528.16 \pm 3.60$ & $1253.84 \pm 9.40$ & $23.08 \pm 3.21$ & $0.387 \pm 0.017$ & $41.83 \pm 1.56$ & $3.65 \pm 0.50$ & $4.65 \pm 0.51$ & $0.58 \pm 0.06$ & $32.01 \pm 1.40$ \\
\hline 19.04 & $535.28 \pm 1.80$ & $1229.56 \pm 4.80$ & $23.98 \pm 2.43$ & $0.393 \pm 0.009$ & $43.45 \pm 1.28$ & $3.72 \pm 0.38$ & $4.70 \pm 0.54$ & $0.56 \pm 0.04$ & $34.2 \pm 3.40$ \\
\hline 25.0 & $550.81 \pm 2.40$ & $1211.28 \pm 7.40$ & $24.38 \pm 1.16$ & $0.397 \pm 0.024$ & $44.39 \pm 1.56$ & $3.76 \pm 0.40$ & $4.74 \pm 0.52$ & $0.54 \pm 0.02$ & $35.21 \pm 2.10$ \\
\hline 28.2 & $563.62 \pm 3.40$ & $1195.22 \pm 8.20$ & $25.57 \pm 2.41$ & $0.399 \pm 0.018$ & $45.34 \pm 1.38$ & $3.80 \pm 0.41$ & $4.78 \pm 0.55$ & $0.53 \pm 0.04$ & $38.33 \pm 1.20$ \\
\hline \multicolumn{10}{|l|}{ BB-11 } \\
\hline 11.16 & $605.28 \pm 1.60$ & $1240.32 \pm 2.20$ & $20.02 \pm 2.26$ & $0.448 \pm 0.011$ & $33.98 \pm 0.89$ & $3.29 \pm 0.38$ & $3.92 \pm 0.41$ & $0.51 \pm 0.02$ & $28.32 \pm 1.18$ \\
\hline 13.78 & $610.81 \pm 4.60$ & $1222.74 \pm 4.50$ & $20.98 \pm 1.21$ & $0.449 \pm 0.008$ & $33.56 \pm 1.12$ & $3.33 \pm 0.22$ & $3.95 \pm 0.43$ & $0.50 \pm 0.01$ & $30.11 \pm 1.15$ \\
\hline 19.09 & $620.28 \pm 3.20$ & $1209.25 \pm 3.60$ & $21.87 \pm 1.56$ & $0.452 \pm 0.006$ & $34.01 \pm 1.08$ & $3.35 \pm 0.25$ & $3.98 \pm 0.39$ & $0.49 \pm 0.03$ & $32.18 \pm 2.01$ \\
\hline 25.21 & $626.86 \pm 2.40$ & $1188.11 \pm 4.80$ & $22.97 \pm 2.12$ & $0.455 \pm 0.017$ & $34.68 \pm 1.23$ & $3.37 \pm 0.31$ & $4.01 \pm 0.46$ & $0.47 \pm 0.05$ & $34.54 \pm 1.87$ \\
\hline 28.35 & $632.62 \pm 2.20$ & $1179.18 \pm 2.60$ & $23.57 \pm 1.05$ & $0.458 \pm 0.020$ & $35.87 \pm 0.79$ & $3.38 \pm 0.35$ & $4.03 \pm 0.45$ & $0.46 \pm 0.08$ & $36.33 \pm 1.58$ \\
\hline
\end{tabular}

Values are mean \pm SE. GMD-Geometric mean diameter; AMD-Arithmetic mean diameter; AOR-Angle of repose 
Table 2. Variation of static coefficient of friction at variable moisture content on different surfaces

\begin{tabular}{clll}
\hline Moisture content $(\% \mathrm{db})$ & Ply wood & Mild Steel & Galvanized Iron \\
\hline MTU-1010 & & & \\
11.11 & $0.47 \pm 0.02$ & $0.62 \pm 0.01$ & $0.43 \pm 0.02$ \\
13.63 & $0.56 \pm 0.03$ & $0.64 \pm 0.02$ & $0.46 \pm 0.03$ \\
19.04 & $0.59 \pm 0.02$ & $0.71 \pm 0.03$ & $0.54 \pm 0.01$ \\
25.0 & $0.64 \pm 0.02$ & $0.75 \pm 0.01$ & $0.58 \pm 0.02$ \\
28.2 & & $0.78 \pm 0.01$ & $0.63 \pm 0.02$ \\
BB-11 & $0.43 \pm 0.02$ & & \\
11.16 & $0.46 \pm 0.02$ & $0.58 \pm 0.01$ & $0.39 \pm 0.01$ \\
13.78 & $0.56 \pm 0.02$ & $0.63 \pm 0.01$ & $0.44 \pm 0.02$ \\
19.09 & $0.62 \pm 0.01$ & $0.70 \pm 0.04$ & $0.56 \pm 0.02$ \\
25.21 & $0.69 \pm 0.02$ & $0.76 \pm 0.02$ & $0.62 \pm 0.03$ \\
28.35 & & $0.79 \pm 0.03$ & $0.68 \pm 0.01$ \\
\hline
\end{tabular}

Values are mean $\pm \mathrm{SE}$

The linear regression models for all the properties were developed considering the highest coefficient of determination and lowest standard error (Table 3 and Table 4).

Table 3. Regression model as a function of moisture content for the different physical properties of paddy varieties

\begin{tabular}{|c|c|c|c|c|c|c|}
\hline \multirow{2}{*}{ Property } & \multicolumn{3}{|c|}{ MTU-1010 } & \multicolumn{3}{|c|}{ BB-11 } \\
\hline & Regression Equation & $\mathrm{R}^{2}$ & $\mathrm{P}$ & Regression Equation & $\mathrm{R}^{2}$ & $\mathrm{P}$ \\
\hline Bulk density & $3.0951 \mathrm{~m}+606.920$ & 0.962 & 0.035 & $5.0822 \mathrm{~m}+680.120$ & 0.983 & 0.031 \\
\hline True density & $-4.323 m+1142.60$ & 0.957 & 0.020 & $-2.286 m+1128.80$ & 0.977 & 0.041 \\
\hline Test weight & $0.1814 m+20.336$ & 0.989 & 0.019 & $0.1622 \mathrm{~m}+20.261$ & 0.985 & 0.012 \\
\hline Sphericity & $0.0008 \mathrm{~m}+0.377$ & 0.987 & 0.018 & $0.0006 \mathrm{~m}+0.395$ & 0.982 & 0.046 \\
\hline Surface area & $0.2515 \mathrm{~m}+38.331$ & 0.986 & 0.033 & $0.2615 \mathrm{~m}+38.243$ & 0.988 & 0.022 \\
\hline $\begin{array}{l}\text { Geometric mean } \\
\text { diameter }\end{array}$ & $0.013 \mathrm{~m}+3.312$ & 0.985 & 0.039 & $0.0107 m+3.4985$ & 0.984 & 0.026 \\
\hline $\begin{array}{c}\text { Arithmetic mean } \\
\text { diameter }\end{array}$ & $0.0093 \mathrm{~m}+4.5156$ & 0.986 & 0.030 & $0.0061 \mathrm{~m}+3.8604$ & 0.983 & 0.022 \\
\hline Porosity & $-0.0039 m+0.6377$ & 0.978 & 0.034 & $-0.0028 m+0.5411$ & 0.991 & 0.042 \\
\hline Angle of repose & $0.4341 \mathrm{~m}+25.544$ & 0.966 & 0.028 & $0.3241 \mathrm{~m}+26.284$ & 0.986 & 0.048 \\
\hline
\end{tabular}

$\mathrm{m}$ : moisture content (d.b.) $\mathrm{R}^{2}$ : Coefficient of determination, $\mathrm{P}<0.05$ : significant at $5 \%$ level of significance

Table 4. Regression model for static coefficient of friction as a function of moisture content on different surfaces

\begin{tabular}{cccccccc}
\hline \multirow{2}{*}{ Property } & \multicolumn{3}{c}{ MTU-1010 } & \multicolumn{3}{c}{ BB-11 } \\
\cline { 2 - 7 } & Regression Equation & $\mathrm{R}^{2}$ & $\mathrm{P}$ & Regression Equation & $\mathrm{R}^{2}$ & $\mathrm{P}$ \\
\hline Ply wood & $0.0096 \mathrm{~m}+0.3641$ & 0.978 & 0.035 & $0.0149 \mathrm{~m}+0.2638$ & 0.989 & 0.027 \\
Mild Steel & $0.0094 \mathrm{~m}+0.517$ & 0.988 & 0.034 & $0.012 \mathrm{~m}+0.4597$ & 0.986 & 0.038 \\
Galvanized Iron & $0.0113 \mathrm{~m}+0.3083$ & 0.985 & 0.046 & $0.0166 \mathrm{~m}+0.2168$ & 0.983 & 0.032 \\
\hline
\end{tabular}

$\mathrm{m}$ : moisture content (d.b.) $\mathrm{R}^{2}$ : Coefficient of determination, $\mathrm{P}<0.05$ : significant at $5 \%$ level of significance

\subsection{Bulk density}

The bulk density of the paddy varied between $514.76 \mathrm{~kg} / \mathrm{m}^{3}$ to $563.62 \mathrm{~kg} / \mathrm{m}^{3}$ for MTU-1010 variety and $605.28 \mathrm{~kg} / \mathrm{m}^{3}$ to $632.62 \mathrm{~kg} / \mathrm{m}^{3}$ for BB-11 variety in the experimental moisture range. When the paddy grain is slender, the porosity increases and bulk density decreases ${ }^{[17]}$. MTU-1010 paddy variety is slender than BB-11 paddy variety, hence the bulk density of MTU-1010 is less than BB-11. The bulk density of the paddy varieties at different moisture content are given in Table 1 . The bulk density was found to increase with the increase of moisture content in both the paddy varieties. The increase in 
bulk density with increase in moisture content might be attributed to the fact that the increase in volume was less than the corresponding increase in mass of the material. Similar results were obtained while determining the physical properties of raw and parboiled paddy ${ }^{[18]}$. An increase in bulk density was observed with increase in moisture content while studying the important engineering properties of paddy ${ }^{[19]}$. The regression models were found significant at $\mathrm{P}<0.05$ for both the paddy varieties. The coefficient of determination $\mathrm{R}^{2}$ for MTU-1010 and BB-11 were 0.962 and 0.983 respectively (Table 3).

\subsection{True density}

The true density of the paddy ranged between $1271.61 \mathrm{~kg} / \mathrm{m}^{3}$ to $1195.22 \mathrm{~kg} / \mathrm{m}^{3}$ for MTU-1010 variety and $1240.32 \mathrm{~kg} / \mathrm{m}^{3}$ to $1179.18 \mathrm{~kg} / \mathrm{m}^{3}$ for BB-11 variety in the experimental moisture range. The true density was found to decrease with the increase of moisture content in both the paddy varieties. The decrease in true density with increase in moisture content might be due to the increase in the volume of the kernel in relation to mass of the kernel. The regression analysis showed negative linear relationship and was found significant $(\mathrm{P}<0.05)$ with coefficient of determination $\mathrm{R}^{2} 0.957$ and 0.977 for MTU-1010 and BB-11 variety respectively (Table 3). Similar observation were reported while conducting studies on different varieties of paddy ${ }^{[18,19]}$.

\subsection{Test weight}

The test weight (1000 grain weight) for the two paddy varieties increased significantly with the increase in moisture content. The test weight of the paddy varied between $22.25 \mathrm{~g}$ to $25.57 \mathrm{~g}$ for MTU-1010 variety and $20.02 \mathrm{~g}$ to $23.57 \mathrm{~g}$ for BB-11 variety in the experimental moisture range. The increase in test weight was observed due to the increase in moisture content. A similar increasing trend have been reported for hemp seed ${ }^{[20]}$ and jatropa seed ${ }^{[21]}$. The regression models were found significant $(\mathrm{P}<0.05)$ for both the paddy varieties with coefficient of determination $\mathrm{R}^{2} 0.989$ and 0.985 for MTU1010 and BB-11respectively.

\subsection{Sphericity}

The sphericity varied between 0.386 to 0.399 for MTU-1010 variety and 0.448 to 0.458 for BB-11 variety in the experimental moisture range. The sphericity was found to increase with the increase of moisture content in both the paddy varieties. The increase in sphericity with increase in moisture content might be due to the increase in the values of three linear dimensions, which were observed to increase. The regression analysis showed positive linear relationship and was found significant $(\mathrm{P}<0.05)$ with coefficient of determination $\mathrm{R}^{2} 0.987$ and 0.982 for MTU-1010 and BB-11 variety respectively (Table 3 ). Same observation was reported while conducting studies on different varieties of paddy ${ }^{[18,22]}$. The low sphericity values in case of both the paddy varieties is due to the cylindrical shape of paddy. Hence, mathematical models for soaking or drying characteristics of paddy can be developed considering the cylindrical shape of the paddy instead of sphere.

\subsection{Surface area}

The variation of surface area with moisture content of both the paddy varieties are given in Table 1 . It was observed that surface area increased significantly with increase in moisture content for both the paddy varieties. It can be observed that surface area of the paddy increased linearly from 40.92 to $45.44 \mathrm{~mm}^{2}$ for MTU-1010 variety and 33.98 to $35.87 \mathrm{~mm}^{2}$ for BB-11 variety in the experimental moisture range. Regression models were found significant for both the varieties $(\mathrm{P}$ $<0.05$ ). The coefficient of determination $\left(\mathrm{R}^{2}\right)$ for MTU-1010 and BB-11 variety were 0.986 and 0.988 respectively (Table $3)$. The increase in surface area might be attributed to the increase in size of the paddy grain due to absorption of moisture. Similar results were reported for fenugreek ${ }^{[23]}$ and linseed ${ }^{[24]}$ respectively.

\subsection{Porosity}

The porosity of the paddy varied between 0.60 to 0.53 for MTU-1010 and 0.51 to 0.46 for BB-11 variety in the experimental moisture range which indicated the linear decrease of porosity with increase in moisture content. Regression models were found significant for both the varieties $(\mathrm{P}<0.05)$. The coefficient of determination $\left(\mathrm{R}^{2}\right)$ for $M T U-1010$ and BB-11 variety were 0.983 and 0.985 respectively (Table 3 ). The reason for this decrease is that since the paddy absorbs moisture, its volume decreases resulting in decrease of the number of grains per unit volume thereby decreasing the porosity of the bed. Similar results were reported with hemp seed ${ }^{[20]}$ and dried pomegranate seeds ${ }^{[25]}$ respectively.

\subsection{Angle of repose}

The angle of repose ranged between 30.96 to $38.33^{\circ}$ for MTU-1010 variety and 28.32 to $36.33^{\circ}$ for $\mathrm{BB}-11$ in the experimental moisture range. The angle of repose was found to increase with the increase of moisture content in both the paddy varieties. The increase in angle of repose with increase in moisture content might be due to the increase in the cohesiveness of the grains among themselves at higher moisture content thereby ensuring greater bonding among the grains and leading to higher angle of repose. The regression analysis showed positive linear relationship and was found 
significant $(\mathrm{P}<0.05)$ with coefficient of determination $\mathrm{R}^{2} 0.966$ and 0.986 for MTU-1010 and BB-11 variety respectively (Table 3). Similar trends were observed for hemp seed ${ }^{[20]}$, millet ${ }^{[26]}$, amaranthus ${ }^{[27]}$ and cowpea ${ }^{[28]}$.

\subsection{Static coefficient of friction}

The static coefficient of friction of paddy grains on three surfaces, namely plywood, mild steel, and galvanized iron is reported in Table 2. It was observed that the static coefficient of friction of paddy grains increased significantly with moisture content against all the experimental surfaces. This might be attributed to the increased cohesiveness between the material surfaces and the paddy grains at higher moisture contents leading to increased $\mu$ values. Similar trends have been observed for squash, sunflower and faba bean ${ }^{[15,29,30]}$. The regression analysis showed positive linear relationship and was found significant $(\mathrm{P}<0.05)$ with coefficient of determination $\mathrm{R}^{2}>0.90$ for MTU-1010 and BB-11 variety respectively (Table 3).

\subsection{Amylose content}

The amylose content in MTU-1010 and BB-11 variety as determined by the standard procedure was found to be $30.23 \%$ and $26.32 \%$ respectively. International Rice Research Institute, Philippines has categorized the different paddy varieties based on their amylose content. Paddy varieties having less than $20 \%$ amylose have been categorized into low amylose paddy varieties and those varieties having amylose content more than $25 \%$ have been categorized into high amylose paddy varieties. The paddy varieties having amylose content between $20-25 \%$, i.e., intermediate amylose paddy is preferred for consumption as rice in most paddy-growing areas of the world. It can be inferred from the above discussion that the paddy varieties used in our study belongs to the high amylose paddy category. Due to its high amylose content these varieties have poor digestibility, lacks palatability and often regarded as low grade paddy varieties. Hence these varieties need to be converted into easily digestable product through mechanical/chemical process before consumption. Flaking is one such mechanical operation which causes extensive physical damage to the amylose structure, resulting in the formation of easily digestible rice flakes. Hence, high amylose paddy varieties are generally used for flaking paddy.

\subsection{Pasting characteristics}

The values of RVA pasting properties like Peak viscosity (PV), Pasting temperature (PT), trough viscosity (TV), final viscosity (FV), breakdown viscosity (BD) and setback viscosity (SB) of the rice flour samples of MTU-1010 and BB-11 are presented in Figure 1.

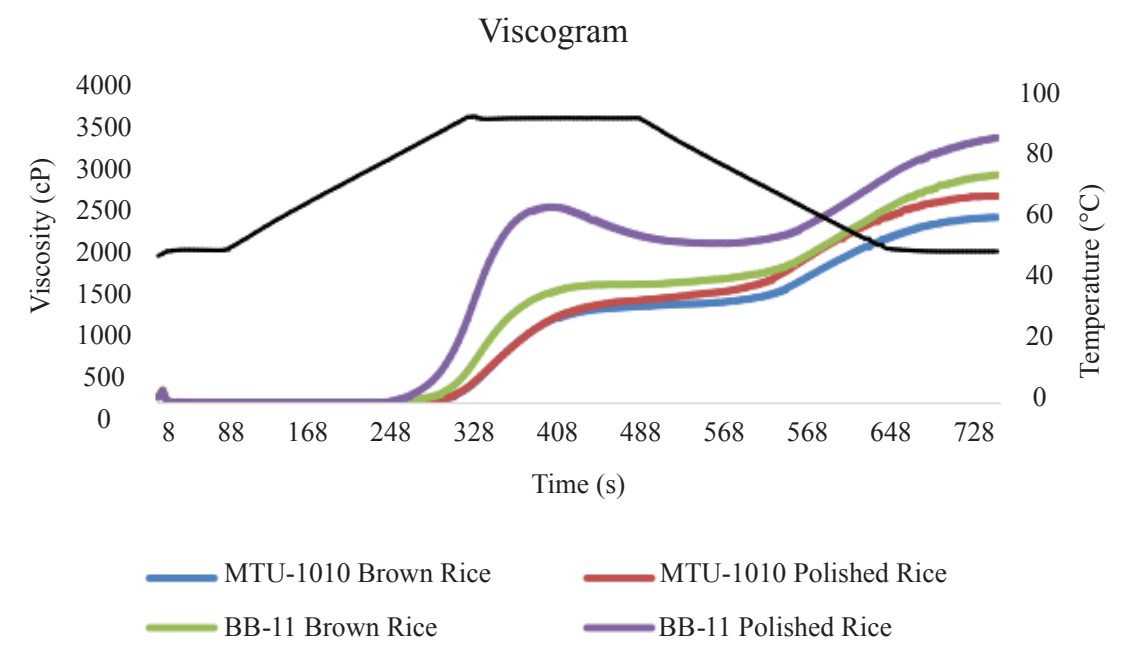

Figure 1. Viscosity curve of four rice flour samples as determined by Rapid Viscosity Analyzer (RVA)

BB-11 variety showed high breakdown and peak viscosity than MTU-1010 as shown in Figure 1. The starch granules of rice with high breakdown demonstrated the ease of breaking of starch granules when heated after the maximum swelling at the peak viscosity. The pasting temperature is also influenced by the amylose content where high pasting temperature is associated with high amylose content and vice-versa. It was observed that pasting temperature of MTU-1010 (91.2 $\left.{ }^{\circ} \mathrm{C}\right)$ is more than BB-11 $\left(88.1^{\circ} \mathrm{C}\right)$ owing to higher amylose content in MTU-1010 (Table 5). 
Table 5. Rapid Viscosity Analysis of polished and brown rice for MTU-1010 and BB-11 variety

\begin{tabular}{|c|c|c|c|c|c|c|c|}
\hline Sample & $\begin{array}{l}\text { Peak viscosity } \\
\text { (cP) }\end{array}$ & $\begin{array}{l}\text { Trough viscosity } \\
\text { (cP) }\end{array}$ & $\begin{array}{l}\text { Breakdown } \\
\text { viscosity }(\mathrm{cP})\end{array}$ & $\begin{array}{c}\text { Final Viscosity } \\
(\mathrm{cP})\end{array}$ & $\begin{array}{c}\text { Setback viscosity } \\
\text { (cP) }\end{array}$ & Peak Time (min) & $\begin{array}{c}\text { Pasting Temp } \\
\left({ }^{\circ} \mathrm{C}\right)\end{array}$ \\
\hline $1 \mathrm{BA}$ & $1250 \pm 2.8$ & $1088 \pm 3.2$ & $162 \pm 1.2$ & $2448 \pm 6.2$ & $1360 \pm 8.2$ & $7 \pm 0.2$ & $91.2 \pm 2.1$ \\
\hline $1 \mathrm{PA}$ & $1328 \pm 1.8$ & $1101 \pm 2.6$ & $227 \pm 2.1$ & $2728 \pm 4.5$ & $1627 \pm 5.6$ & $7 \pm 0.6$ & $90.4 \pm 1.2$ \\
\hline $2 \mathrm{BA}$ & $1560 \pm 3.5$ & $1464 \pm 4.1$ & $96 \pm 1.1$ & $3008 \pm 5.2$ & $1544 \pm 3.2$ & $6.93 \pm 0.3$ & $88.1 \pm 2.2$ \\
\hline $2 \mathrm{PA}$ & $2194 \pm 2.8$ & $1348 \pm 1.6$ & $846 \pm 2.2$ & $2831 \pm 6.3$ & $1483 \pm 4.5$ & $5.2 \pm 0.2$ & $81.95 \pm 2.1$ \\
\hline
\end{tabular}

MTU-1010 brown rice-1BA, polished rice-1PA; BB-11 brown rice-2BA, polished rice-2PA; Values are mean $\pm \mathrm{SE}$

The setback value indicates the degree of retrogradation of a starch paste. BB-11 variety provided lower setback viscosity than MTU-1010 variety. Similar observations were made while studying the pasting properties of flours from different Thai Rice cultivars ${ }^{[31]}$.

\subsection{Dynamic rheological behaviour}

The rheogram in Figure 2 shows the temperature-dependent storage modulus ( $\left.\mathrm{G}^{\prime}\right)$ of brown and polished rice flour suspension of MTU-1010 and BB-11 varieties. The storage modulus represents the elastic portion of viscoelastic behaviour, which explains the solid state behaviour of the sample and as well as give information about the stored deformation energy. The loss modulus characterizes the viscous portion of the viscoelastic behaviour, which can be seen as the liquid state behaviour of the sample. It also represents the deformation energy lost through internal friction when flowing. Viscoelastic solids have a higher storage modulus than loss modulus ( $\left.G^{\prime}>G^{\prime \prime}\right)$ whereas viscoelastic liquids have a higher loss modulus than storage modulus $\left(G^{\prime \prime}>G^{\prime}\right)$. Storage modulus $\left(G^{\prime}\right)$ and loss modulus (G") were determined using the Rheometer during dynamic rheological measurements of rice flour. G' of polished rice flour of MTU-1010 and BB-11 variety showed same patterns. G' started to increase suddenly at temperatures of $65^{\circ} \mathrm{C}$ and reached peak at $90^{\circ} \mathrm{C}$ signifying the swelling of starch granules and gelatinization at the same temperature. The initial increase in $\mathrm{G}^{\prime}$ was caused by swelling of starch granules and close packing of granules in the suspension ${ }^{[32]}$. The increase in $G^{\prime}$ might be a result of an irreversible starch granules swelling, crystallites melting, or component leaching of starch granules ${ }^{[33]}$. However, G' of polished rice flour of MTU-1010 was higher than that of polished rice flour of BB-11 variety which might due to the high amylose content in MTU-1010 variety. It was also observed that the G' of brown rice of both the paddy varieties were more than the polished rice of both the varieties. The increase in G' might be attributed to the presence of bran (fibrous portion) in brown rice than in polished rice. Further, G' for both the paddy varieties was greater than G", indicating the viscoelastic solid behaviour (loss factor $\tan \delta<1)$, with MTU-1010 exhibiting higher viscoelastic behaviour. 


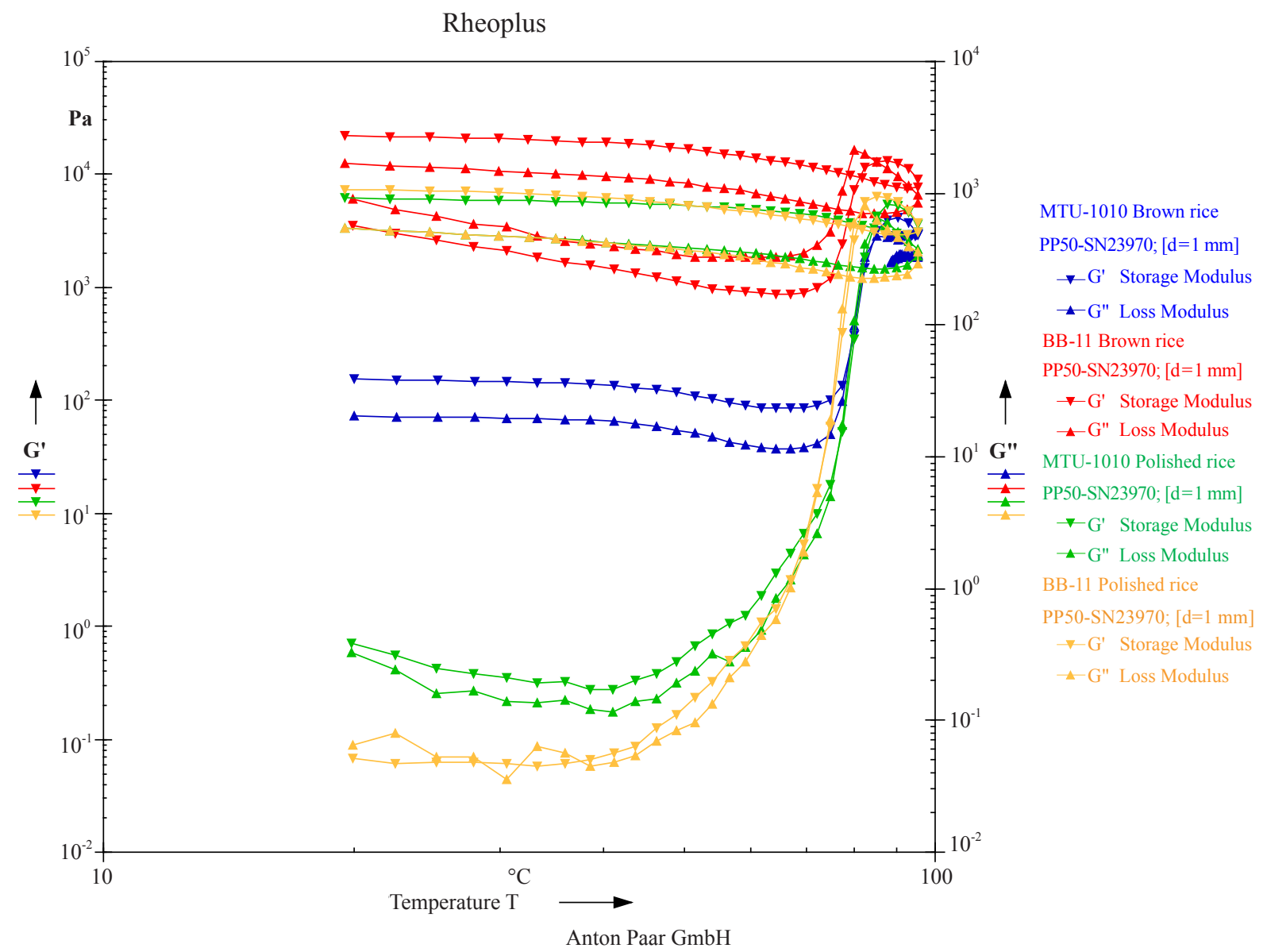

Figure 2. Rheogram showing storage and loss modulus of rice flour of paddy variety MTU-1010 and BB-11

\section{Conclusion}

The study was conducted to find the various physical properties, pasting characteristics and rheological behaviour of paddy varieties (MTU-1010 and BB-11) suitable for flaking. The grain physical properties were evaluated in relation to moisture content which was varied between $11.11 \%$ to $28.2 \%$ (d.b.). The bulk density increased for all the studied varieties of paddy with increase in moisture content. The porosity of both the varieties decrease with increase in moisture content. All other properties like test weight (1000 grain mass), surface area, arithmetic mean diameter, geometric mean diameter and angle of repose increased with the increase in studied range of moisture content. The regression analysis revealed that all the developed linear regression models $(\mathrm{P}<0.05)$ can be used to predict the physical properties of both the paddy varieties with an accuracy of more than 0.90 . The amylose content in MTU-1010 and BB-11 variety was $30.23 \%$ and $26.32 \%$ respectively indicating that high amylose containing paddy varieties are generally used for flaking paddy. It was also observed that BB-11 paddy variety provided higher peak and breakdown viscosity and lower setback and pasting temperature than MTU-1010 variety. The rheological studies indicated higher storage modulus of brown rice than the polished rice for both the paddy varieties.

\section{Acknowledgment}

Authors acknowledge the Director, ICAR-Central Institute of Post-Harvest Engineering and Technology, Ludhiana, Punjab, India for providing different facilities and support during this research.

\section{References}

[1] Press Information Bureau, Government of India, Ministry of Agriculture \& Farmers Welfare. Available from: http:// pib.nic.in/newsite/PrintRelease.aspx?relid=183146. [Accessed 21st November 2018]. 
[2] Kumar S., Haq R., Prasad K. Studies on physico-chemical, functional, pasting and morphological characteristics of developed extra thin flaked rice. Journal of the Saudi Society of Agricultural Sciences. 2016; 17: 259-267.

[3] Basavaraj G., Raviteja D., Shrinivas. Physical properties of rice for puffing. International Journal of Latest Trends in Engineering and Technology. 2015; 5: 376-380.

[4] Ashwini P. Effect of moisture content on gravimetric and frictional properties of ridge gourd seed (Luffa Actangula Roxb). Agricultural Engineering. 2014; 2: 33-42.

[5] Zareiforoush H., Komarizadeh M.H., Alizadeh M.R. Effect of moisture content on some physical properties of paddy grains. Research Journal of Applied Sciences, Engineering and Technology. 2009; 1: 132-139.

[6] Chukwu O., Sunmonu M.O. Determination of selected engineering properties of cowpea (Vigna unguiculata) related to design of processing machines. International Journal of Engineering and Technology. 2010; 6: 373-378.

[7] AOAC International. Official methods of analysis. 13th ed. Arlington: Association of Official Analytical Chemist; 1980.

[8] Deshpande S.D., Bal S., Ojha T.P. Physical properties of soybean. J. Agric. Eng. Res. 1993; 56: 89-98.

[9] Singh K.K., Goswami T.K. Physical properties of cumin seed. J. Agric. Eng. Res. 1996; 64: 93-98.

[10] Carman K. Some physical properties of lentil seeds. J. Agric. Eng. Res. 1996; 63: 87-92.

[11] Cetin M. Physical properties of barbunia bean (Phaseolus vulgaris L. cv. 'Barbunis') seed. J. Food Eng. 2007; 80: 353-358.

[12] Mohsenin N.N. Physical Properties of Plant and Animal Materials. New York: Gordon and Breach; 1986.

[13] Jain R.K., Bal S. Physical properties of pearl millet. J. Agric. Eng. Res. 1997; 66: 85-91.

[14] Joshi D.C., Das S.K., Mukherjee R.K. Physical properties of pumpkin seeds. J. Agric. Eng. Res. 1993; 54(3): 219229.

[15] Paksoy M., Aydin A. Some physical properties of edible squash (Cucurbita pepo L.). J. Food Eng. 2004; 65: 225-231.

[16] American Association of Cereal Chemists. Criteria and tests for rice grain qualities. In: Juliano BO. (ed.). Rice: Chemistry and Technology. 2nd ed. St. Pual, MN: American Association of Cereal Chemists; 1985. p. 443-524.

[17] Bhattacharya K.R. Rice Quality: A Guide to Rice Properties and Analysis. Amsterdam: Elsevier; 2011.

[18] Reddy B.S., Chakraverty A. Physical properties of raw and parboiled paddy. Biosyst. Eng. 2004; 88: 461-466.

[19] Pandiselvam R., Thirupathi V. Important engineering properties of paddy. Scientific Journal. Agricultural Engineering. 2014; 4: 73-83.

[20] Sacilik K., Ozturk R., Keskin R. Some physical properties of hemp seed. Biosyst. Eng. 2003; 86: 191-198.

[21] Garnayak D.K., Pradhan R.C, Naik S.N., Bhatnagar N. Moisture-dependent physical properties of Jatropha seed (Jatropha curcas L.). Ind. Crops Prod. 2008; 27: 123-129.

[22] Rasaq A.A.A., Lateef O.S., Hameed O.O., Olayinka R.K. Effect of variety and moisture content on some engineering properties of paddy rice. J. Food Sci. Technol. 2011; 48: 551-559.

[23] Altuntas E., Özgöz E., Taser Ö.F. Some physical properties of fenugreek (Trigonella foenum-graceum L.) seeds. $J$. Food Eng. 2005; 71: 37-43.

[24] Selvi K.C., Pinar Y., Yesiloglu E. Some physical properties of linseed. Biosyst. Eng. 2006; 95: 607-612.

[25] Kingsly A.R.P., Singh D.B., Manikantan M.R., Jain R.K. Moisture dependent physical properties of dried pomegranate seeds (Anardana). J. Food Eng. 2006; 75: 492-496.

[26] Konak M., Carman K., Aydin C. Physical properties of chickpea seeds. Biosyst. Eng. 2002; 82: 73-78.

[27] Ilori T.A., Akinyele O.A. Effect of moisture content on selected engineering properties of amaranthus cruentus seed. International Journal of Emerging Technology and Advanced Engineering. 2016; 6: 126-131.

[28] Firouzi S., Alizadeh M. Effect of moisture content on selected physical characteristics of cowpea seed (Vigna unguiculata L. Walp). Annals of Biological Research. 2012; 3: 3583-3590.

[29] Gupta R.K., Das S.K. Physical properties of sunflower seeds. J. Agric. Eng. Res. 1997; 66: 1-8.

[30] Altuntas E., Yı1dı M. Effect of moisture content on some physical and mechanical properties of faba bean (Vicia faba L.) grains. J. Food Eng. 2007; 78: 174-183.

[31] Varavinita S., Shobsngobb S., Varanyanondc W., Chinachotid P., Naivikule O. Effect of amylose content on gelatinization, retrogradation and pasting properties of flours from different cultivars of Thai Rice. Starch. 2003; 55: 410-415.

[32] Hsu S., Lu S.C., Huang R.M. Viscoelastic changes of rice starch suspensions during gelatinization. J. Food Sci. 2000; 65: 215-220.

[33] Rao M.A., Tattiyakul J. Granule size and rheological behavior of heated tapioca starch dispersions. Carbohydr. Polym. 1999; 38: 123-132. 